\title{
Inequalities in availability of National Health Service general dental practitioners in England and Wales
}

\author{
D. R. Moles, ' C. Frost, ${ }^{2}$ C. Grundy, ${ }^{3}$
}

\begin{abstract}
Aim To model the inequalities in availability of National Health Service general dental practitioners in England and Wales in relation to key socio-demographic factors.

Methods Current estimates of the numbers of NHS general dental practitioners for each health authority were related to data from the 1991 census using Poisson regression models, and generalised estimating equations to allow for correlation between results for neighbouring health authorities.

Results An 'average' health authority, without a dental school, would be expected to have 2,138 residents for every NHS dentist. Controlling for relevant factors, health authorities with higher proportions of the following are associated with lower (better) population to dentist ratios by the amounts shown: each $1 \%$ higher female population $(-11.8 \%$; 95\%CI $-19.1 \%,-3.9 \%$ $P=0.004)$; each $1 \%$ greater South Asian population $(-1.4 \%$; $95 \% \mathrm{CI}-2.1 \%,-0.7 \% P<0.001)$. A health authority with a dental school is associated with a more favourable ratio compared with one without such a facility $(-9.2 \% ; 95 \% \mathrm{CI}-16.2 \%,-1.6 \%$ $P=0.019)$. Each additional $1 \%$ of the following are associated with a worse ratio by the amounts shown: children aged 0 to 14 years old $(+5.2 \%$; $95 \% \mathrm{CI}+2.4 \%,+8.1 \% P<0.001)$; adults aged over 65 years old $(+2.8 \%, 95 \% \mathrm{CI}+1.0 \%,+4.7 \% P=0.002)$; households without a car $(+0.8 \%$; 95\% CI $0.0 \%,+1.6 \% P=0.042)$. Conclusions Ensuring access to dental care may be a more complex issue than simply providing adequate numbers of dentists at a national level. Any manpower planning exercise should additionally consider local factors that may act as incentives or disincentives to those professionals who provide care.
\end{abstract}

$\mathrm{D}$ entists provide almost all the oral health care in the United Kingdom. The Dentists Act currently permits only minimal duties to be undertaken by the professions complementary to dentistry (PCDs), such as hygienists and dental therapists. There are currently just over 29,000 persons registered to practice dentistry in the UK and around 4,000 PCDs. ${ }^{1}$ The British Dental Association (BDA) estimates that there are around 20,000 dentists in general

$1^{*}$ Clinical Lecturer and MRC Special Fellow in Health Services Research, Oral Pathology Department, Eastman Dental Institute, University College London;

${ }^{2}$ Senior Lecturer in Medical Statistics, Medical Statistics Unit, London School of Hygiene and Tropical Medicine; ${ }^{3}$ Lecturer in Geographical Information Systems, Environmental Epidemiology Unit, London School of Hygiene and Tropical Medicine

${ }^{*}$ Correspondence to: Dr Moles, Oral Pathology Department, Eastman Dental

Institute for Oral Health Care Sciences, University College London, 256 Gray's Inn

Road, London WC1X 8LD

email: dmoles@eastman.ucl.ac.uk

REFEREED PAPER

Received 16.02.00; Accepted 26.10.00

(c) British Dental Journal 2001; 190: 548-553 practice who provide at least some NHS care, and approximately $500-1,000$ purely private dentists. ${ }^{2}$

The UK as a whole had a population to dentist ratio of 2,485 to 1 in 1994. This was the second least favourable ratio among European Union countries. ${ }^{3}$ The BDA has stated its belief that there is insufficient dental manpower and has called for manpower requirements to be reassessed. ${ }^{4}$ The General Dental Council has requested that government change the 1984 Dentist's Act to permit a wider skillmix of personnel to be employed in the provision of dental services. This occurred as a result of the recommendations published in a review of the role of PCDs. ${ }^{5}$

Individuals and professional organisations have expressed concerns about dental manpower; in particular regarding the geographical maldistribution of general dental practitioners. However, there is relatively little information in the literature to guide policy. The most frequently cited studies were conducted more than 20 years ago. ${ }^{6-9}$ Recently, Buck considered inequalities in numbers of general dental practitioners both in terms of the relationship to population size and, importantly, in relation to inequalities in oral health. ${ }^{10} \mathrm{He}$ reported that the inequalities in manpower were worse when compared with oral health than they were when compared solely with population size. Reducing inequalities in health became one of the main health policy issues of the late 1990s. ${ }^{11}$ The independent inquiry into inequalities in health collected evidence and reviewed recommendations for tackling the public health problems arising from these inequalities. ${ }^{12}$

Much is known about the factors that affect demand for services from consumers of healthcare. People from higher socio-economic groups are more likely to register with a dentist and are more likely to attend for check-ups when they do not have symptoms. ${ }^{13,14}$ A recent survey undertaken by the National Consumer Council reported that registration was higher in the higher social groups $(81 \%)$ than in the lower social groups $(67 \%) .{ }^{15}$ Selfreported registration was also higher in females (79\%) than males $(71 \%)$. In each case the reported levels of registration are higher than the actual levels recorded by the Dental Practice Board. ${ }^{16}$ In most industrialised countries the socio-economic gradient in the use of dental services is well documented, not only in terms of relatively lower frequency of dental visits for low-income and less educated groups, but also in relation to lower consumption of preventive services. ${ }^{17}$

Relatively little research has focussed on the supply-side of the dental manpower equation. Taylor et al. hypothesised 'If more were known about the factors which influence dentists' choice of practice location, the knowledge might then be used to redress the imbalance.' ${ }^{18}$ The aim of the current investigation was to construct a model to describe and predict the geographical inequalities in availability of NHS general dental practitioners in England and Wales in relation to key socio-demographic factors. 


\section{Methods}

Data preparation

The numbers of dentists providing NHS dental care within each of the 105 English and Welsh health authorities were estimated from the numbers of NHS contracts for each health authority. These were derived from the January to March 1999 Dental Practice Board bulletin. ${ }^{16}$ The DPB data were also used to calculate current total population estimates for each health authority. Socio-demographic data were extracted from the 'small area statistics' tables of the 1991 census. Since the health authority boundaries changed in 1996, it was not appropriate to extract the data at the level of 1991 health authorities. These data were therefore extracted at the enumeration district level (ED) level and were aggregated to the 1996 district health authority level by combining EDs using the geographical information systems (GIS) software package ARCINFO. ${ }^{19}$

The data were used to generate a series of possible factors (covariates) that might explain the variations in the relationship between population size for a health authority and the number of general dental practitioners with a NHS contract. All proportions were calculated from the 1991 census data.

\section{Statistical methods}

Poisson regression models were fitted to the data to investigate the relationship between the numbers of NHS practitioners and the potential explanatory factors. The analyses accounted for the differing population sizes in the different health authorities. Further statistical techniques were employed to account for the

Table I Population per NHS dentist in each health authority in 1999

\begin{tabular}{|c|c|c|c|}
\hline Health authority & $\begin{array}{l}\text { People per } \\
\text { NHS dentist }\end{array}$ & Health authority & $\begin{array}{l}\text { People per } \\
\text { NHS dentist }\end{array}$ \\
\hline Kensington, Chelsea \& Westminster & 1214 & Birmingham & 2210 \\
\hline Camden and Islington & 1378 & Sefton & 2222 \\
\hline Ealing, Hammersmith and Hounslow & 1407 & Bradford & 2226 \\
\hline East Norfolk & 1495 & North and Mid Hampshire & 2228 \\
\hline Brent and Harrow & 1550 & Morecambe Bay & 2232 \\
\hline West Hertfordshire & 1593 & Suffolk & 2237 \\
\hline Barnet & 1605 & North West Lancashire & 2242 \\
\hline Croydon & 1614 & West Pennine & 2253 \\
\hline East and North Hertfordshire & $168 \mid$ & North Cumbria & 2262 \\
\hline Manchester & 1697 & Gwent & 2273 \\
\hline East Surrey & 1715 & Somerset & 2274 \\
\hline Enfield and Haringay & 1732 & Wiltshire & 2279 \\
\hline Merton, Sutton and Wandsworth & 1737 & Leicestershire & 2288 \\
\hline Avon & 1737 & North Nottinghamshire & 2295 \\
\hline Tees & 1782 & Rotherham & 2298 \\
\hline Sheffield & 1829 & Isle of Wight & 2331 \\
\hline Kingston and Richmond & 1833 & Portsmouth \& SE Hampshire & 2347 \\
\hline West Surrey & 1836 & Oxfordshire & 2358 \\
\hline West Sussex & 1848 & Bury and Rochdale & 2359 \\
\hline Wirral & 1863 & Coventry & 2360 \\
\hline Newcastle and North Tyneside & |89| & East Kent & 2364 \\
\hline Leeds & 1894 & East Lancashire & 2400 \\
\hline East Sussex, Brighton and Hove & 1899 & Worcestershire & 2402 \\
\hline Hillingdon & 1904 & Bro Taf & 2406 \\
\hline North and East Devon & 1922 & Southampton \& SW Hampshire & 2409 \\
\hline Lambeth, Southwark and Lewisham & 1940 & North Cheshire & 2437 \\
\hline Nottingham & 1940 & County Durham & 2443 \\
\hline Liverpool & 1965 & Shropshire & 2454 \\
\hline West Kent & 1967 & Cambridge and Huntingdon & 2481 \\
\hline Herefordshire & 1977 & South Essex & 2482 \\
\hline Buckinghamshire & 1981 & North Wales & 2523 \\
\hline East London and The City & 1998 & South Derbyshire & 2526 \\
\hline Redbridge and Waltham Forest & 2006 & Dyfed Powys & 2528 \\
\hline Bexley and Greenwich & 2032 & Warwickshire & 2531 \\
\hline Bromley & 2038 & St Helens and Knowsley & 2542 \\
\hline Gateshead and South Tyneside & 2044 & Bedfordshire & 2557 \\
\hline South and West Devon & 2067 & South Lancashire & 2566 \\
\hline Stockport & 2068 & Cornwall and Isles of Scilly & 2566 \\
\hline North Yorkshire & 2072 & Barnsley & 2585 \\
\hline Berkshire & 2077 & Sunderland & 2593 \\
\hline Salford and Trafford & 2096 & Wakefield & 2601 \\
\hline North Essex & 2120 & North Staffordshire & 2659 \\
\hline Wigan and Bolton & 2125 & Wolverhampton & 2661 \\
\hline Lechyd Morgannwg & 2127 & Solihull & 2699 \\
\hline Gloucestershire & 2143 & Northamptonshire & 2787 \\
\hline Doncaster & 2144 & North West Anglia & 2831 \\
\hline Calderdale and Kirklees & 2165 & South Staffordshire & 2904 \\
\hline Dorset & 2176 & East Riding & 2932 \\
\hline North Derbyshire & 2177 & Lincolnshire & 2935 \\
\hline South Cheshire & 2183 & Dudley & 2938 \\
\hline Sandwell & 2189 & South Humber & 2981 \\
\hline Northumberland & 2205 & Walsall & 3359 \\
\hline Barking and Havering & 2207 & & \\
\hline
\end{tabular}




\section{RESEARCH \\ dental practice}

Table 2. Summary statistics of health authority socio-demographic data

\begin{tabular}{|c|c|c|c|c|c|}
\hline Item & Mean & Minimum & Maximum & $\begin{array}{r}\operatorname{Ref} \\
(2.5 \%, \varsigma\end{array}$ & $\begin{array}{l}\text { gge } \\
\text { centiles) }\end{array}$ \\
\hline Population density (people/ $/ \mathrm{km}^{2}$ ) & $|56|$ & 43 & 11234 & 61 & 8781 \\
\hline Postcode density (postcodes $/ \mathrm{km}^{2}$ ) & 48.3 & 2.3 & $56 I .1$ & 2.7 & 282. I \\
\hline Proportion of the population who are non-white (\%) & 5.8 & 0.4 & 37.3 & 5.3 & 29.8 \\
\hline Proportion of the population who are Black (\%) & 1.7 & 0.1 & 18.7 & 0.1 & 12.3 \\
\hline Proportion of the population who are South Asian (\%) & 2.9 & 0.1 & 19.2 & 0.1 & 15.7 \\
\hline Proportion female (\%) & 51.5 & 50.4 & 53.3 & 50.5 & 52.8 \\
\hline Proportion aged $0-14$ years old (\%) & 18.9 & 13.2 & 23.0 & 16.3 & 21.8 \\
\hline Proportion aged I 5-64 years old (\%) & 65.0 & 60.1 & 72.3 & 60.8 & 68.8 \\
\hline Proportion aged over 65 years old $(\%)$ & 16.1 & 12.4 & 23.4 & 12.4 & 22.9 \\
\hline Proportion of unemployed men (\%) & 11.4 & 5.7 & 25.8 & 5.9 & 23.4 \\
\hline Proportion of households without a car (\%) & 24.8 & 10.7 & 51.4 & II.8 & 49.5 \\
\hline Proportion of households not owner occupied (\%) & 32.0 & 20.5 & 68.5 & 21.4 & 63.1 \\
\hline Proportion of overcrowded households (\%) & 4.6 & 2.3 & 19.4 & 2.5 & 10.5 \\
\hline
\end{tabular}

Table 3 Univariate relationships between 199 I census variables and the 1999 estimated population to NHS dentist ratios for English and Welsh health authorities

\begin{tabular}{|c|c|c|c|c|}
\hline Item & $\begin{array}{l}\text { Predicted change in } \\
\text { population to dentist ratio (\%) }\end{array}$ & \multicolumn{2}{|c|}{$95 \%$ confidence interval (\%) } & $P$ \\
\hline Each 100 people per $\mathrm{km}^{2}$ increase in the population density & -0.41 & -0.28 & -0.54 & $<0.001$ \\
\hline Each 100 postcodes per $\mathrm{km}^{2}$ increase in the postcode density & -11.23 & -8.13 & -14.24 & $<0.001$ \\
\hline Changing from a rural to an urban health authority & & & & \\
\hline (cut-off point at I,000 people per $\mathrm{km}^{2}$ ) & -9.84 & -3.44 & -15.82 & 0.003 \\
\hline Changing from a non-London to a London health authority & -21.50 & -14.99 & -27.52 & $<0.001$ \\
\hline Each $1 \%$ increase in proportion of females & -10.96 & -6.14 & -15.54 & $<0.001$ \\
\hline Each $1 \%$ increase in proportion aged 0 to 14 years old & +4.62 & +2.20 & +7.10 & $<0.001$ \\
\hline Each $1 \%$ increase in proportion aged over 65 years old & +0.34 & -1.16 & +1.87 & 0.657 \\
\hline Each $1 \%$ increase in proportion of unemployed men & -0.47 & $-1.3 \mid$ & +0.38 & 0.281 \\
\hline Each $1 \%$ increase in proportion of households not owning a car & -0.42 & -0.07 & -0.78 & 0.020 \\
\hline Each $1 \%$ increase in proportion of overcrowded households & $-|.8|$ & -0.66 & -2.95 & 0.002 \\
\hline Each $1 \%$ increase in proportion of households not owner-occupied & -0.61 & -0.28 & -0.94 & $<0.001$ \\
\hline Each $1 \%$ increase in proportion of the population who are non-white & -0.89 & -0.51 & -1.26 & $<0.001$ \\
\hline Each I\% increase in proportion of the population who are Black & -1.88 & -1.01 & -2.74 & $<0.001$ \\
\hline Each $1 \%$ increase in proportion of the population who are South Asian & -1.03 & -0.25 & $-1.8 \mid$ & 0.009 \\
\hline Changing from a health authority without a dental school to one with a dental school & -11.03 & -1.80 & -19.40 & 0.020 \\
\hline
\end{tabular}

geographical relationships between the health authorities. The statistical methods are described in detail in the appendix.

\section{Results}

Table 1 lists all 105 health authorities in England and Wales along with the total population size divided by the number of NHS dentists. The health authority with the most favourable ratio was Kensington, Chelsea and Westminster (1,214 residents per NHS dentist). The least favourable ratio was found in Walsall (3,359 residents per NHS dentist). These results are presented geographically in Figure 1. Table 2 shows summary information for the health authority explanatory covariates. Table 3 presents the results obtained from univariate Poisson regression analyses. The results are the estimated effects for each of the explanatory covariates without controlling for the effects of any of the other covariates or allowing for correlation between results for neighbouring health authorities.

Table 4 shows the relationship between the statistically significant $(P<0.05)$ covariates in the final model and the population to dentist ratios derived using a Generalised Estimating Equation approach as described in the appendix. The reference point is a hypothetical 'average' health authority with average proportions of all the listed covariates and no dental school. An 'average' health authority would be expected to have 2,138 residents per NHS dentist. Health authorities with greater proportions of females are associated with statistically significantly lower numbers of people per NHS dentist. Statistically significantly lower ratios are also seen in health authorities with a relatively high proportion of the population who are South Asian, with a higher proportion of households that are not owner-occupied, and in health authorities with a dental school. The population to dentist ratios are statistically significantly worse in health authorities with relatively high proportions of the population being made up of children (0-14 years old) or older adults (65+ years old), and a relatively large proportion of households without car ownership. Table 4 also shows the non-statistically significant associations between the other covariates and the population to dentist ratio estimated by introducing these covariates, one at a time, into the final regression model.

\section{Discussion}

Since 1990, when the new general dental service contract was introduced, the provision of NHS dentistry has been changing. Some practitioners have opted out of the NHS and some are more restrictive in their provision of NHS care. The National Consumer Council's survey asked people if they had attempted to register with a NHS dentist in the last year and whether they had experienced any difficulties in registering. They found that of the $19 \%$ of people who had attempted to register with a NHS practitioner 33\% had experienced difficulty in doing so. This was a slightly higher proportion than found in the Council's previous survey in 1993, in which $28 \%$ had reported problems. ${ }^{15}$

The existing research into the supply of dental manpower has predominantly focussed on the characteristics of individual dentists. There is a strong relationship between the choice of practice location and factors such as the dentists' place of birth, and the location of both their undergraduate and postgraduate dental education. ${ }^{18,22,23}$ Consideration has also been given to how the practising 


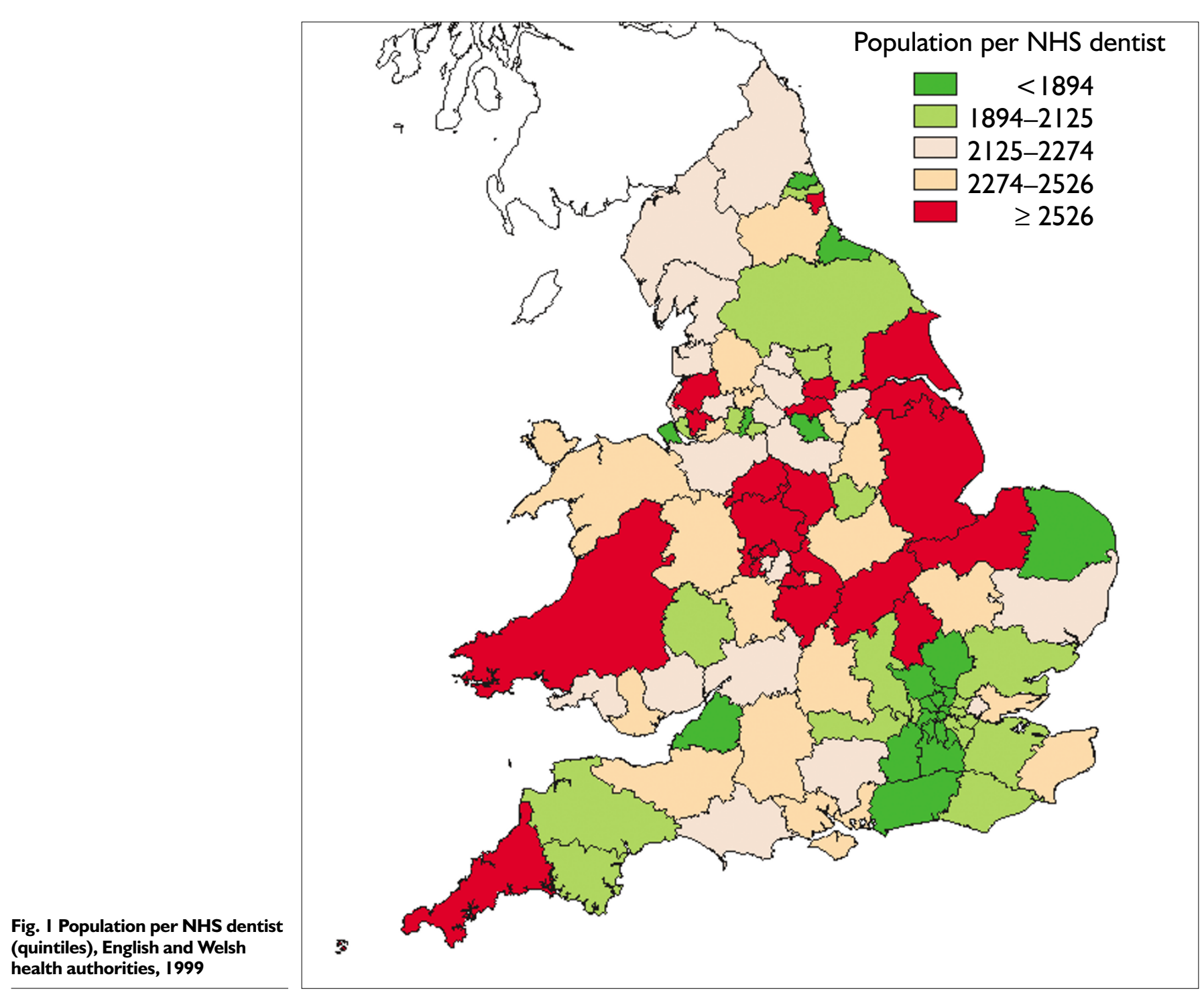

environment may affect the physical and psychological wellbeing of practitioners. Baldwin et al., looked at factors that affected where young dentists worked and the levels of occupational stress they endured. They found that most pressure at work was associated with practitioners who received an income from part NHS and part private funding. ${ }^{24}$ Croucher et al., questioned 325 general dental practitioners about 'burnout' and their working environment. Those practitioners reporting high levels of depersonalisation were more likely to provide a greater proportion of care through the NHS. ${ }^{25}$

The current investigation differs from previous research in that it uses routinely collected data to investigate the relationship between availability of NHS GDPs and demographic characteristics of the population they potentially serve. The health authority was chosen as the unit of analysis for two reasons; one scientific and one pragmatic. The analysis at the health authority level makes sense since this is the level at which local policy decisions will be made. The Dental Practice Board also publishes details of registrations and contracts at this level. There is evidence within social and health services literature that the health authority level may not be the most appropriate level at which to undertake these types of investigations. Census data are collected at a much lower level. As areas are combined, the effect of aggregation is to lose sensitivity since larger areas are more homogenous than smaller areas. Thus differences in social structure may be lost. This is amply illustrated by an investigation of the relationship between caries experience in 5 and 12-year-old children and the Jarman index of relative deprivation by Jones et al.
Their study found that the smaller the geographical units under study the stronger the association between caries and deprivation. ${ }^{26}$

The DPB publishes the number of contracts that it holds with practitioners in each health authority. This will never correspond exactly to number of dentists providing NHS care, and cannot measure what proportion of their work is undertaken under private arrangements. Some practitioners may have recently stopped seeing NHS patients but will have a contract with the DPB if they are waiting for payment for work completed. Some practitioners may be working as an assistant to another dentist and will not hold a personal contract with the Dental Practice Board. Some dentists will work in more than one health authority and will hold more than one contract. Similarly, among attenders, there is no guarantee that people will visit a dental practice in their health authority of residence (although most probably do).

Previous studies have shown an association between dental attendance, oral health, and demographic factors. Dental attendance is in part governed by individual patient factors, but may also be related to the availability of services. The current study has demonstrated that availability of NHS dental practitioners is itself also related to local demographic factors, albeit at an ecological level. A model can be used to describe those factors that are associated with the number of NHS dental practitioners in a health authority. Inequalities in the numbers of NHS dentists are apparent between different health authorities when controlling for the total population size of each health authority. 


\section{RESEARCH dental practice}

Table 4 Relationships between 199 I census variables and the 1999 estimated population to NHS dentist ratios for English and Welsh health authorities after controlling for statistically significant covariates

\begin{tabular}{|c|c|c|c|c|}
\hline \multirow{2}{*}{$\begin{array}{l}\text { Item } \\
\text { Covariates in final model }\end{array}$} & \multirow[t]{2}{*}{$\begin{array}{c}\text { Predicted change in } \\
\text { population to } \\
\text { dentist ratio }(\%)\end{array}$} & \multicolumn{2}{|c|}{$\begin{array}{l}95 \% \text { confidence interval } \\
(\%)\end{array}$} & \multirow[t]{2}{*}{$P$} \\
\hline & & & & \\
\hline Each $1 \%$ increase in proportion of females & -11.8 & -19.1 & -3.9 & 0.004 \\
\hline Each $1 \%$ increase in proportion aged 0 to 14 years old & +5.2 & +2.4 & +8.1 & $<0.001$ \\
\hline Each $1 \%$ increase in proportion aged over 65 years old & +2.8 & +1.0 & +4.7 & 0.002 \\
\hline Each $1 \%$ increase in proportion of households not owning a car & +0.8 & 0.0 & +1.6 & 0.042 \\
\hline Each $1 \%$ increase in proportion of households not owner occupied & -0.6 & -1.2 & 0.0 & 0.040 \\
\hline Each I\% increase in proportion of South Asian people & -1.4 & -2.1 & -0.7 & $<0.001$ \\
\hline Changing from a health authority without a dental school to one with a dental school & -9.2 & -16.2 & -1.6 & 0.019 \\
\hline \multicolumn{5}{|l|}{ Non-statistically significant covariates } \\
\hline Each 100 people per $\mathrm{km}^{2}$ increase in the population density & +0.3 & -0.1 & +0.7 & 0.140 \\
\hline Each 100 postcodes per $\mathrm{km}^{2}$ increase in the postcode density & +0.9 & -6.9 & +9.3 & 0.831 \\
\hline Changing from a rural to an urban health authority (cut-off point at $I, 000$ people per $\mathrm{km}^{2}$ ) & +5.0 & -3.0 & +13.5 & 0.226 \\
\hline Changing from a non-London to a London health authority & +9.9 & -3.9 & +25.6 & 0.168 \\
\hline Each $1 \%$ increase in proportion of unemployed men & -0.3 & -2.3 & +1.6 & 0.735 \\
\hline Each $1 \%$ increase in proportion of overcrowded households & +2.6 & -0.3 & +5.6 & 0.077 \\
\hline Each $1 \%$ increase in proportion of the population who are non-white & +0.7 & -0.4 & +1.9 & 0.188 \\
\hline Each $1 \%$ increase in proportion of the population who are Black & $+\mathrm{I} . \mathrm{I}$ & -0.2 & +2.3 & 0.095 \\
\hline
\end{tabular}

Health authorities in which there are relatively higher proportions of females appear to be better served for NHS GDPs than health authorities with lower proportions of women. However, it should be noted that the range between the areas with the lowest and highest proportions of females is less than $3 \%$ (Table 2) and so caution should be exhibited when interpreting this result. The fact that health authorities with a dental school appear to have around a $9 \%$ improvement in the population to NHS dentist ratio supports previous research that dentists often choose to practise near where they qualified or undertook postgraduate training. It was also found that health authorities with a large South Asian population were also relatively better-served. Dentistry is a career that is a popular choice among the Indian community ${ }^{27}$ and previous research has shown that dentists often return to their place of childhood to practice (although ethnicity has not been specifically considered). ${ }^{18,22,23}$ Car ownership and property ownership may be considered as proxies for affluence. In the current study they were both of borderline statistical significance. The importance of these proxy measures can be difficult to assess. In highly urbanised areas car ownership becomes less important than in rural communities. Similarly, ownership of property may be a less effective measure of affluence in certain city areas. The only factors that were clearly associated with lower availability of NHS GDPs were the proportions of the local population who are either young ( $\leq 14$-years-old) or elderly ( $\geq 65$-years-old). This would tend to reinforce the notion that dentistry is predominately a market for young and middle-aged adults.

As long ago as 1981 the Dental Strategy Review Group stated 'We believe that minimising the existing social and geographical differences in dental care will require a co-ordinated manpower policy and cannot be left to chance as hitherto.'28 Buck points out that little has been done since. His work shows that the inequalities in numbers of GDPs in relation to current treatment need are worse than the inequalities in population to dentist ratios. ${ }^{10}$ Neither the work of Buck or the current study are able to account for the contribution made by independent (private) practitioners or the Community Dental Service (CDS). The number of entirely private practitioners is relatively small. Although part of the remit of the CDS is to provide care to people who may experience difficulty in accessing care from the general dental service, its overall contribution is small in comparison with the much larger number of dentists in general practice.

\section{Conclusions}

The current investigation was conducted at an ecological level and was based on census data that is relatively old. As such, it cannot provide conclusive proof of associations. However, it does indicate that the process of ensuring equitable access to dental care may be a more complex issue than simply providing adequate numbers of dentists or dental auxiliaries at a national level. In addition to consideration of the well-documented barriers to access experienced by potential clients, any manpower planning exercise should consider local factors that act as incentives or disincentives to those professionals who will be expected to provide dental care. Failure to consider these factors may not address the underlying inequality in service provision and might even exacerbate the problem.

The authors wish to acknowledge the kind assistance of Professor Michael Kenward and Dr Mona Abdalla, Medical Statistics Unit, London School of Hygiene and Tropical Medicine. This research arose following a suggestion by Professor Raman Bedi, Eastman Dental Institute. Dr Moles was part funded by a Medical Research Council Advanced Course Studentship. The source of the demographic data used in this study is: the 1991 Census, Crown Copyright. ESRC purchase.

\section{Appendix - detailed statistical methodology}

A series of univariate Poisson regression models were fitted to the data to investigate the relationship between the numbers of NHS practitioners and each of the covariates individually. The population size was included as an offset in all the models to account for the different underlying population base for each health authority. In order to facilitate the statistical analyses and interpretations, each of the covariates was centred on its mean by subtracting the mean value for each covariate from the actual value for each health authority. Standard errors were scaled according to the deviance of the models to allow for overdispersion that is likely to arise from the fact that many dentists work in group practices. A model with multiple explanatory covariates was developed to account for the relationship between the number of NHS dentists and each covariate while controlling for the effects of the other covariates included in the model. This model was produced using an automated backward stepwise technique and confirmed by manually checking that it was not possible to re-introduce any of the eliminated covariates at the $5 \%$ level of statistical significance.

Geographically adjacent health authorities exhibited similarities in their dentist to population ratios. The Pearson residuals from the 
final Poisson regression model indicated that a correlation of 0.204 remained for health authorities that shared a boundary after allowing for the explanatory covariates. In order to allow for these similarities, the final model was refitted and confirmatory analysis repeated using a 'generalised estimating equation' approach. ${ }^{20}$ A $105 \times 105$ covariance matrix was specified for the 105 English and Welsh health authorities. This matrix took the value of 1 on the leading diagonal, 0.204 where health authorities were geographically adjacent and 0 in all other cases. Thus the covariance structure was defined as 1 where a heath authority was compared with itself; 0.204 when compared with a neighbour and 0 when compared with a health authority that did not share a common boundary. All the analyses were undertaken using the STATA statistical software package (version 5). ${ }^{21}$

A normal plot of residuals showed a very good fit to the data. The plot showed a single outlier representing East Norfolk health authority which has a considerably more favourable population to dentist ratio $(1,495: 1)$ than the ratio predicted by the model $(2,139: 1)$. In order to ensure that this result was not spurious, a sensitivity analysis was undertaken using 1991 population estimates rather than current estimates. The result was almost identical with East Norfolk remaining as the one outlier.

1 General Dental Council. The Dentists Register. London 1999. Available online at: www.gdc-uk.org/register

2 British Dental Association. Dental facts and figures. London 1999. Available online at: www.bda-dentistry.org.uk/public/figures.

3 Eaton K A, Widstoem E A, Renson C E. Changes in the numbers of dentists and dental caries levels in 12-year-olds in the countries of the European Union and economic area. JR Soc Health 1998; 118: 40-48.

4 British Dental Association. Manifesto for dentistry. London. July, 1996.

5 General Dental Council. Professions Complementary to Dentistry. London May, 1999.

6 Cook P J, Walker R O. The geographical distribution of dental care in the United Kingdom: Part 1 - Sources of information, methods of presentation, distribution of dentists. Br Dent J 1967; 122: 441-447.

7 Cook P J, Walker R O. The geographical distribution of dental care in the United Kingdom: Part 2 - Changes between 1952 and 1962. Br Dent J 1967; 122: 494-499.

8 Cook P J, Walker R O. The geographical distribution of dental care in the United Kingdom: Part 3 - Regional synthesis and discussion. Br Dent $J$ 1967; 122: 451-459.

9 Scarrott D M. Changes in the regional distribution of general dental service manpower. Br Dent J 1978; 144: 359-63.
10 Buck D. Dental health, population size and the distribution of general dental practitioners in England. Commun Dent Health 1999; 16: 149-153.

11 Watt R, Sheiham A. Inequalities in oral health: a review of the evidence and recommendations for action. Br Dent J 1999; 187: 6-12.

12 Independent Inquiry into Inequalities in Health. Chairman, Sir Donald Acheson. London: Stationary Office, 1998.

13 Eddie S, Davies J A. The effect of social class on attendance frequency and dental treatment received in the General Dental Service in Scotland. $\mathrm{Br}$ Dent J 1985; 159: 370-372.

14 Pavi E, Kay E J, Stephen K W. The effect of social and personal factors on the utilisation of dental services in Glasgow, Scotland. Community Dent Health 1995; 12: 208-215.

15 National Consumer Council. Consumer Concerns 1998 - A consumer view of health services, the report of an RSL survey. London: September 1998.

16 Dental Practice Board. Registrations - GDS Quarterly Statistics. JanuaryMarch 1999 England and Wales. June 1999. Available online at: www.dentanet.org.uk/dental.data

17 Petersen P E, Holst D. Utilization of dental health services. In Cohen L K, Gift H C (eds) Disease Prevention and Oral Health Promotion. pp341-386. Copenhagen: Munksgaard, 1995.

18 Taylor G O, Holloway P J, Lennon M A. A factor influencing dentists' choice of practice location. Br Dent J 1976; 141: 154-156.

19 ARCINFO. Environmental Systems Research Institute Incorporated. 1996.

20 Burton P, Gurrin L, Sly P. Extending the simple linear regression model to account for correlated responses: an introduction to generalised estimating equations and multi-level mixed modelling. Stat Med 1998; 17: 1261-1291.

21 STATA version 5. STATA Corporation. Texas 1995.

22 Fyffe H E, Pitts N B. Origin, training and subsequent practice location of Scotland's General and Community dentists. Community Dent Oral Epidemiol 1989; 17: 325-329.

23 O'Brien K D, Roberts C. An analysis of the effects of place of childhood, undergraduate and postgraduate education upon the regional distribution of specialist orthodontic practitioners. Br Dent J 1991; 171: 280-282.

24 Baldwin P J, Dodd M, Rennie J S. Young dentists - work, wealth, health and happiness. Br Dent J 1999; 186: 30-36.

25 Croucher R, Osborne D, Marcenes W, Sheiham A. Burnout and issues of the work environment reported by general dental practitioners in the United Kingdom. Community Dent Health 1998; 15: 40-43.

26 Jones C, Taylor G, Woods K, Whittle G, Evans D, Young P. Jarman underprivileged area scores, tooth decay and the effect of water fluoridation. Community Dent Health 1997; 14: 156-160.

27 Bedi R, Gilthorpe M S. Ethnic and gender variations in university applicants to United Kingdom medical and dental schools. Br Dent J 2000; 189: 212-215.

28 Department of Health and Social Security. Towards better dental health guidelines for the future. Report of the Dental Strategy Review Group. London: HMSO, 1981 